JCCA Volume 6, Issue 2 and 3, Autumn 2019

\title{
Everyday Legend: Reinventing Tradition in Chinese Contemporary Art
}

\section{Editorial}

Jiang Jiehong

During the early development of the People's Republic of China, major cities were industrialised and historical architecture was severely neglected. The Cultural Revolution (1966-76) provided an extraordinary example of political mobilisation directed against the material and cultural vestiges of the past. ${ }^{1}$ During the infamous movement of the Red Guards, China's public properties and cultural relics were attacked and numerous art treasures and artefacts were destroyed. The Open-Door policy beginning in 1978 instigated another 'revolution' - of economic reform and urban transformation. Thirty years of rapid urbanisation have meant that few traditional constructions have survived, and even the buildings and complexes built during the early PRC proved to be transitory, once they had been removed, reconstructed or replaced.

Since the 1980 , the pace of globalisation and the force of its reshaping influences have posed a serious threat to the sustainability of tradition within Chinese arts and culture, as Western architecture, furniture, fashion and products have permeated Chinese cities; which has seen the gradual transformation of the everyday into an 'internationalised' style of living. Urbanisation and tourism have turned Chinese traditional art and crafts from indigenous to touristic and commercial, from the 'local' to 'global'. Traditional design and hand-making skills in numerous productions, such as textiles, porcelain, wood-and stonecarving, are declining, either because their craftsmanship lacks the avenues of future inheritance and transmission, or because they have been substituted by the cursory processes of batch production for tourists. Now, much of what is described as 'traditional' is no longer part of an everyday reality, but is instead an item of material culture ranging from

\footnotetext{
${ }^{1}$ From a general understanding, the Great Proletarian Cultural Revolution was launched in 1966 by Mao Zedong for his political agenda and ended with his demise in 1976. It is often referred to as the 'ten lost years' or, metaphorically, as a 'cultural desert' (wenhua shamo); most of the cultural outcomes of the Cultural Revolution are seen as valueless. However, in fact, Mao's legacy has been deeply embedded by virtue of the sheer scale of the mass movement for visual productions. We developed a special issue (JCCA 5.2\&3), Making the New World: The Arts of China's Cultural Revolution, discussing the significance of the arts and culture of the Cultural Revolution, and to reflect upon their impacts on everyday experience in China within socio-political, cultural and global contexts.
} 
discrete displays of museum cases to monumental structures of national and historical significance. Such popular reactions to these prevailing conditions broadly represent the state of anxiety, an anxiety of seeking the cultural root.

To reflect critically upon this anxiety, we started the research project, Everyday Legend, ${ }^{2}$ funded by the Leverhulme Trust with a leading research question: will tradition reinvent the past for the future and translate from China to the world? The notion of translation here is adopted as metaphor for the common object of enquiry with which all the project participants aim to engage via diverse disciplines, methods and categories of expertise/experience. Past, future, China and the world summon basic paradigms of the humanities' common interest in time and space, basic access points that each participant will extend into disciplinary engagements as diverse as art history, sociology, cultural studies, creative industries and tourism. Tradition stands in the first instance for the heritage - including its intangible dimensions - of cultural activities and products whose possible extinction is now sharply profiled by relentless social adjustments to standardised industrial production, transnational distribution, mass marketing, centralised media flows, and patterns of imagination that stress the global ahead of the national ahead of the local.

According to Homi Bhabha, 'the recognition that tradition bestows is a partial form of identification. In re-staging the past it introduces other, incommensurable cultural temporalities into the invention of tradition'. ${ }^{3}$ Today, in China, traditions are interrupted, fragmented or distorted. This unique situation represents a certain degree of disorientation, confusion and frustration, but at the same time, offers both opportunities and challenges, particularly, in the field of art, as traditions are constantly reassessed, reinvented, and alternatives in unexpected categories and in new forms of expression. Chinese contemporary artists stand in various positions favourable to reimagining, appropriating and subverting the processes that traditional craft has long used, harnessing their symbolic potential and exploiting their cultural and historical resonances. Through their practices, artists re-examine, draw from and are inspired by traditions, which include techniques, forms and materials, as well as aspects of their intangible cultural heritages; they reflect

\footnotetext{
2 This Leverhulme International Network project $\left(19^{\text {th }}\right.$ September 2016 to $18^{\text {th }}$ September 2018 ) is initiated and led by the Centre for Chinese Visual Arts at Birmingham City University as Lead Institution and it comprises of other five key partners from China, Britain, Europe and Asia Pacific, namely, the New Century Art Foundation (Beijing), the Central Academy of Fine Arts (Beijing), the University of Groningen (Groningen), Goldsmiths, University of London (London) and the White Rabbit Contemporary Chinese Art Collection (Sydney). For more details of this research project, please visit www.everydaylegend.org.

3 Bhabha, Homi, The Location of Culture. London: Routledge, 1994, p. 3.
} 
critically upon their current status and its implications to the present and future, and ultimately, they reposition Chinese contemporary art in the international arena.

In its early development, Chinese contemporary art was recognised in the West merely as a symbol of the existence of free individual spirit within the structure of collectivism. ${ }^{4}$ Or through the experience of the Cultural Revolution, new art was developed in conjunction with the examination of the visual legacy of Mao. ${ }^{5}$ And yet, today, during a time of development of international art events, cultural traditions have proved to be a mine of a certain energy, an energy that empowers a kind of 'uniqueness' for art production. While this 'uniqueness of a work of art is inseparable from its being imbedded in the fabric of tradition', ${ }^{6}$ the strategy becomes vital for Chinese contemporary art in the context of globalisation, to challenge 'the legitimacy of the West-centric monopoly in intellectual and everyday life', ${ }^{7}$ as alchemy, to recreate the past for the future and to translate China for the world. Most recently, as one of the perspectives of the $57^{\text {th }}$ Venice Biennale, Christine Macel suggested 'the pavilion of traditions', questioning 'tradition no longer from the point of view of customs and behaviours, often associated with religion or morality, but through the lens of dialogue between the old and the recent'. ${ }^{8}$ Artists explore 'not only contemporary or recent history, but also a more distant past ${ }^{\prime},{ }^{9}$ and this is typically true in Chinese contemporary art. In response to the overarching 'Viva Arte Viva' theme of the Venice Biennale, China's 'Continuum' Pavilion unveiled an approach to pursuing 'eternity' in Chinese culture. Through the collaborative works of four artists and artisans, it attempted to set up a conversation between art and crafts, the international and the local, and the contemporary and the traditional.

There are a range of perspectives and levels of engagement with traditions in contemporary art practice. These do not simply encompass the exploration of experimental forms for traditional arts such as Chinese painting and calligraphy; they refer, more broadly, to works

\footnotetext{
$4 \mathrm{Pi}$, Li, 'Between Scylla and Charybdis: the New Context of Chinese Contemporary Art and its Creation since 2000', in Waling Boers and Pi Li (eds.), Touching the Stones: China Art Now, Hong Kong: Timezone 8, 2007, pp. $82-7$.

5 Jiang, Jiehong, The Revolution Continues: New Art from China, London: the Saatchi Gallery and Jonathan Cape, 2008.

${ }^{6}$ Benjamin, Walter, 'The Work of Art in the Age of Mechanical Reproduction', in Hannah Arendt (ed.), Harry Zohn (trans.), Illuminations, New York: Schocken Books, 1969.

7 Hou, Hanru, 'Entropy, Chinese Artists, Western Art's Institutions: A New Internationalism', in Yu Hsiao-Hwei (ed.), On the Mid-Ground, Hou Hanru, Hong Kong: Timezone 8, 2002, p. 62.

${ }^{8}$ Macel, Christine, 'Viva Arte Viva Arte Viva Arte Viva Arte Viva Arte Viva Arte', in $57^{\text {th }}$ International Art Exhibition Viva Arte Viva, La Biennale di Venezia, 2017, p. 24. 9 lbid.
} 
of installation, photography and video, which reveal 'their debt to China's rich artistic heritage by way of translation, transformation, appropriation and refiguration' ${ }^{10}$ Forms, materials and techniques that carry traditional cultural significance appear frequently in contemporary artwork, to name a few, for example, gunpowder (Cai Guo-Qiang, b. 1957), silk (Liang Shaoji, b. 1945), bamboo (Xiao Yu, b. 1965), jade (Zhao Zhao, b. 1982), porcelain (Liu Jianhua, b. 1962), paper-cuts (Lü Shengzhong, b. 1952), literati stone (Zhan Wang, b. 1962), antique books (Xu Bing, b. 1955) and furniture (Ai Weiwei, b. 1957). These approaches of practice are not just about drawing information and inspiration from traditions, but about developing artists' personal reflections and new strategies of visual explorations.

During the Leverhulme project, a major exhibition of Chinese contemporary art had been curated to present work by 19 artists on the topic staged at the Shanghai Minsheng Art Museum. ${ }^{11}$ The show was then re-curated with a selective group of four artists and brought back to England for the audience here and, as part of the conference hosted at the School of Art, Birmingham City University, a final event of the two-year project, to illuminate, inspire and further extend the discussions ${ }^{12}$ It is impossible to introduce extensively all the relevant practices in Chinese contemporary art, but in this Editorial, the following example artworks of the artists who were included in Everyday Legend through the curatorial approach will invite the artists' voice to the discussion and shed some light on the latest practices with the particular concerns rooted in cultural traditions.

Liu Jianhua, who currently works and lives in Shanghai, was initially in fact trained as a ceramic and porcelain craftsman from a young age. ${ }^{13}$ Porcelain, perhaps one of the oldest materials of craftsmanship in China, have always formed the basis of his contemporary work. Through means of ancient firing techniques and traditional processes of making, the artist reflects on today's society. When a certain material becomes part of contemporary

\footnotetext{
10 Wu, Hung, Contemporary Chinese Art: A History (1970s-2000s), London: Thames and Hudson, 2014, pp. 310-51. ${ }^{11}$ Everyday Legend at the Shanghai Minsheng Art Museum (7 November to 7 December 2016) presents work by Hao Liang, He Xiangyu, Hu Xiaoyuan, Liang Shaoji, Liang Yuanwei, Liu Jianhua, Lu Pingyuan, Ni Youyu, Shao Yinong, Shi Jinsong, Sui Jianguo, Sun Xun, Wu Yiming, Yang Mushi, Yang Xinguang, Yu Ji, Zhan Wang, Zheng Guogu and Zhao Zhao.

12 The $11^{\text {th }}$ CCVA Annual Conference: Everyday Legend was hosted at the School of Art, Birmingham City University on 10-11 September 2018 presenting papers by 18 speakers including 4 keynotes, Michael Hitchcock (Goldsmiths), Oliver Moore (Groningen University), Pi Li (M+ Hong Kong) and Qiu Zhijie (CAFA Beijing). The 4 artists of the accompanied conference exhibition from 4 September to 4 October 2018 include Hu Xiaoyuan, Liu Jianhua, Yu Ji and Zhao Zhao.

${ }_{13}$ See details in 'Conversations: Liu Jianhua and Jiang Jiehong', pp. XX-XX.
} 
artistic language, it not only contributes as a set of 'vocabulary', ornate, simple or sophisticated; more importantly, the rules governing the intangibles resulting from the traditional craft and production process constitute the 'grammar' of this language. Filled (Figure 1), for instance, explores the limits of craft techniques within the domain of a traditional 'grammar', as the work converts minute changes observed in the realms of everyday nature into an aesthetic form, and thereby shapes the artist's personal and specific language system. It brings to mind a plate overflowing with crystal-clear spring water, as if disturbed for an instant, its surface still moving with ripples, or animated into a story unfolding in the 'language of porcelain'.

As a younger generation artist, Hu Xiaoyuan makes use of xiao - raw silk sheet, as well as found objects from daily life. As her signature work, the installation Wood (Figure 2) presents nothing but simply a bunch of wood pieces, 31 in total, short or long, leaning on a wall. In fact, they are all meticulously painted - first coloured in white and covered with the translucent fabric. Using ink, the artist then copies onto the surface of xiao the grain and texture of the wood, or in her own words, makes 'new "skins" for these wood pieces', and discovers 'their original limitation, as well as their infinity' in the long process of the work. ${ }^{14}$ In this process, the natural lines of the wood are extracted, replaced, and transformed, and it alters the original properties of the material itself. The artist uses xiao as a medium to make her work, and simultaneously, it is the intervention of this specific material that enables her reflection to acquire its full depth. As a result, the understanding and the transformation summoned by the material come to form a new object, a natural and yet unnatural object.

Trained in Western realistic methods at an art academy for many years, Yu Ji decided to return to a Chinese aesthetic system - a fundamentally different world - and borrowed the plastic language of traditional Buddhist sculpture to craft typical Eastern bodies out of cement. The description of shapes in Chinese language can be literary and sometimes, poetically precise, but never measurable. The work Flesh in Stone (Figure 3) collects a range of components of human bodies, the appearance of which still preserves the rough texture of cement, including the traces of mould rims. These body parts are made in shapes which are dissociated from the Western systematic categories - they are neither 'figurative' nor 'abstract', but something in-between. They are naked, mercilessly affixed to the walls with

$14 \mathrm{Hu}$, Xiaoyuan, artist statement, 2010. 
metal brackets. One might fail to read on these bodies any cultural, social or political identity; even sexual features are attenuated. While these bodies might read fragmentary on the level of physical appearance, in the artist's view, once they are cleared of any identifying symbols, they are in fact more 'complete': they simply become, strictly speaking, 'purer bodies - bodies that have been minutely prepared to exude an Eastern essence'. ${ }^{15}$

Zhao Zhao used jade found in Hotan, Xinjiang, which originally came from the 4,000-metrehigh Kunlun Mountains, to carve an actual-size version of a cheap, mass-produced everyday item - a lighter (Figure 4). The work only preserves the exterior appearance of the plastic lighter, and therefore is naturally devoid of its original functionality. This months-long and meticulous work of exquisite craftsmanship was expended on a daily consumer product that can be manufactured in the blink of an eye or discarded without a thought. Both are to be fondled lovingly, either in the context of elegant traditional culture or in that of the consumerist daily life of our present time, whilst the translucent and supremely luxurious quality of the stone contrarily assumes a cheap and low-grade shape.

The statement of the artist can be more extensive, and powerful. The minimalistic installation Again (cover image) appears as a one and half metre cube comprising hundreds of stone blocks in different sizes, large or small, all confined and consolidated within a single set of dimensions. Each stone block in the geometric shape was in previous incarnation parts of ancient Chinese Buddha statue. Collected by the artist over the years, these Buddha sculptures were already damaged during struggles of Buddhist persecutions in the dynastic China as well as the political campaigns, such as 'smashing the four olds' during the Cultural Revolution. The shapes of the original figures together with their artistic styles and forms and the time of the making, actual or estimated, were eliminated. They are no longer sculpture, or they are new sculpture, abstract and industrial, cut by the electronic blades on a cold machine bed. In the same vein, in the work, Countless, Zhao Zhao further divided the stone these statues are made of into innumerable cubes, each of them with just one centimetre-long edges. They can be displayed as a large mosaic-like floor, or lined up to mark a hundred-metre-long wall (Figure 5). Just like the fierce revolution that took place in the past century, anything of religious, cultural or political religious significance has been thoroughly pulverised by the violence of the machine and 220 volt electricity of our modern

15 See details in 'Conversations: Yu Ji and Jiang Jiehong', pp. xx-XX. 
days.

Tradition travels, from one generation to the next and from one place to another. Through the journey, it evolves, transforms and mutates. The situation of tradition in contemporary China is singular; in art, it can be reinterpreted and reinvented, or completely reborn through alternative, created paths.

*Everyday Legend is a Leverhulme International Network Project (2016-18). 